\title{
Structured Query Language
}

National Cancer Institute

\section{Source}

National Cancer Institute. Structured Query Language. NCI Thesaurus. Code C54108.

An industry-standard language for creating, updating and, querying relational database

management systems. 